\title{
MATERNAL AND PERINATAL OUTCOME IN ECLAMPSIA IN A TERTIARY CARE CENTRE
}

Bharti Choudhary (Parihar), Krishna Akhande

1. Assistant Professor. Department of Obstetrics \& Gynaecology, Sultania Zanana Hospital, Gandhi Medical College, Bhopal, Madhya Pradesh.

2. Resident. Department of Obstetrics \& Gynaecology, Sultania Zanana Hospital, Gandhi Medical College, Bhopal, Madhya Pradesh.

\section{CORRESPONDING AUTHOR:}

Dr. Bharti Choudhary (Parihar), 115/5, OPD Block, Sultania Zanana Hospital Campus,

Bhopal, Madhya Pradesh- 462001.

E-mail: drbhartiparihar@gmail.com

KEY WORDS: Eclampsia, Perinatal outcome, Maternal Mortality, Magnesium Sulphate

ABSTRACT: BACKGROUND: Eclampsia is a life threatening emergency that continues to be a major cause of serious maternal morbidity and is still the leading cause of maternal mortality worldwide. OBJECTIVE: Analysis of all cases of Eclampsia patients to find out the incidence, to evaluate the clinical course, medical \& obstetric management, and complications and to study the maternal \&perinatal outcome. METHODS: This study was a hospital based prospective observational study. We obtained the data for this study from the case records of all Eclampsia patients who admitted in the Department of Obstetrics \& Gynaecology, Gandhi Medical College, Bhopal from 01.01.2011 to 31.12.2011 and data were recorded on a predesigned proforma. All the obstetrical women with convulsions after 20 weeks pregnancy or in postpartum period were evaluated. Each case was documented with respect to age, socioeconomic status, education, occupation, gestational age, time of onset of Eclampsia, duration and frequency of seizures, mode of delivery, use of drugs (anticonvulsant and antihypertensive), maternal and perinatal outcome RESULTS: Out of total 203 Eclampsia patients, 144 cases(70.93\%) were Antepartum Eclampsia, 22 patients (10.84\%) were intrapartum Eclampsia, 35 cases (17.24\%) were postpartum Eclampsia \& 2 cases $(0.9 \%)$ were status Eclampticus.30\% Patients did not have oedema, $14 \%$ had $\mathrm{BP}<140 / 90 \mathrm{~mm}$ of $\mathrm{Hg}$ and $11.4 \%$ did not have proteinuria at the time of admission. There were 21 maternal deaths and morbidity consisted of pulmonary oedema in $31(33.6 \%)$ cases, CVA in $17(18.4 \%)$ cases, renal failure in $7(7.6 \%)$ cases, HELLP syndrome in $6(6.5 \%)$ cases and aspiration pneumonia in $2(2.2 \%)$ cases. Perinatal mortality was $44.3 \%$ with majority being related to extreme prematurity. CONCLUSIONS: There is a need of proper antenatal care to prevent Eclampsia and the need for intensive monitoring of women with Eclampsia throughout the hospitalization to improve both the maternal \& perinatal outcome

INTRODUCTION: Eclampsia is a serious complication of pregnancy responsible for high maternal and foetal mortality \&morbidity. It is an unpredictable, multiorgan disorder unique to human pregnancy. According to Chesley ${ }^{1}$, a description of this syndrome was mentioned in the ancient writings of both the Egyptians and the Chinese. In recent years the reported incidence of Eclampsia ranged from 1 in 110 to 1 in 3448 pregnancies $^{2-4}$.The extremely low incidence reported from Sweden indicates that appropriate prenatal care and early hospitalization of 
patients with Pre-Eclampsia can markedly reduce Eclampsia. Similar findings were reported by Zuspan 5 and Gilstrap et al ${ }^{6}$.

During the study period, 203 cases of Eclampsia were managed at our centre. During same period obstetric attendance was 11,373; giving an incidence of $1.78 \%$.The purpose of this study is to evaluate the clinical course, medical \& obstetric management, complications and to study maternal and perinatal outcome.

MATERIAL \& METHODS: From $1^{\text {st }}$ January 2011 to $31^{\text {st }}$ December 2011,203 consecutive cases of Eclampsia were managed at Sultania Zanana Hospital, Gandhi Medical College, Bhopal. All the obstetrical women admitted in emergency receiving room with convulsions after 20 weeks of gestation or in postpartum period included in this study. Women with other causes of convulsion were excluded. Diagnosis of Eclampsia was confirmed by history taking, general and obstetrical examinations. Specific investigations for Eclampsia- urine albumin by heat coagulation method, CBP, LFT, RFT, Coagulation profile, platelet count and Fundoscopy were performed. All patients were treated with standard intramuscular regimen as recommended by Pritchards $^{7}$ which consisted of 4 gmMagnesium Sulphate given intravenously and 5 gm given intramuscularly on each buttock. Subsequently $5 \mathrm{gm}$ of magnesium sulphate given intramuscularly every 4 hours up to 24 hours following delivery or convulsion whichever is last. Severe hypertension was treated with Inj.Labetalol, initial dose $20 \mathrm{mg}$ IV, followed by $40-80 \mathrm{mg}$ every 10 minutes, until therapeutic response is achieved ${ }^{8}$.As soon as women were stabilized, labour was induced, accelerated or caesarean section done if obstetric indication demanded it.

RESULTS: During study period, total obstetric attendance was 11,373, out of which 203 were with Eclampsia i.e. 1.78\%.Out of these, Antepartum Eclampsia were 144(70.93\%),Intrapartum Eclampsia were 22 (10.84\%), Postpartum Eclampsia were 35(17.24\%) and 2 (0.9\%) were status Eclampticus.

Out of them, $68 \%$ were in age group of $18-25$ years, $22.6 \%$ were in $26-30$ years and $8.37 \%$ were above 30 years. Out of these, only $1.97 \%$ was booked and rest of them were unbooked $98.3 \%$.out of them $48.3 \%$ were primi, $46.8 \%$ were multipara and $4.9 \%$ were grand multipara.

It is important to note that the classical triad used to diagnose pre-Eclampsia was not present in all women with Eclampsia.

Table 1: clinical findings $(n=203)$

\begin{tabular}{|l|l|l|l|}
\hline \multicolumn{2}{|l|}{ Clinical Finding } & Number & Percentage \\
\hline \multicolumn{2}{|l|}{ Hypertension: } & & \\
\hline Severe & $\geq 160 / 110$ & 134 & 66 \\
\hline Mild & $<160 / 110$ & 41 & 20 \\
\hline Relative & $<140 / 90$ & 28 & 14 \\
\hline Proteinuria: & & & \\
\hline Absent & & 23 & 11.4 \\
\hline Significant & $(\geq 2+)$ & 180 & 88.6 \\
\hline
\end{tabular}




\begin{tabular}{|l|l|l|l|}
\hline Edema: & & \\
\hline Absent & & 61 & 30 \\
\hline Pedal & & 91 & 45 \\
\hline Generalized & & 51 & 25 \\
\hline
\end{tabular}

Table 1 shows that $66 \%$ had severe hypertension, $14 \%$ had BP $<140 / 90 \mathrm{~mm}$ of Hg. Significant proteinuria was present in $88.6 \%$ cases. Generalized oedema was present in $25 \%$ cases at the time of admission. Our clinical findings were comparable to that reported by Sibai ${ }^{9}$.

This graph shows that maximum patients of Eclampsia113 (55.7\%) belonged to GA 28 30 weeks, $84(41.4 \%)$ patients belonged to GA > 37weeks and only $6(2.9 \%)$ belonged to GA < 28 weeks. This shows the incidence of Eclampsia is very low before 28 weeks of gestation.

Table 2: Outcome of Pregnancy

\begin{tabular}{|l|l|l|l|}
\hline Sl.No. & Type of delivery & No. of Cases & Percentage (\%) \\
\hline 1 & Vaginal & 147 & 88.5 \\
\hline & $($ a) Non-instrumental & 139 & \\
\hline & (b) Instrumental- & 8 & \\
\hline & 1. Outlet forceps & 6 & \\
\hline & 2 Ventouse & 2 & \\
\hline 2 & Cesarean Section & 16 & 9.1 \\
\hline 3 & Subtotal Hysterectomy & 1 & 0.6 \\
\hline 4 & Died Undelivered & 3 & 1.8 \\
\hline
\end{tabular}

This table shows that out of 203 women, 3 died undelivered. Out of 166 antenatal patients, $147(88.5 \%)$ had vaginal delivery. The incidence of caesarean section was $9.1 \%(16)$. One $(0.9 \%)$ woman underwent laparotomy for rupture of the previous caesarean scar at term and needed a subtotal hysterectomy

\section{Maternal Outcome:}

Table 3: Maternal Complications ( $\mathrm{n}=\mathbf{2 0 3})$

\begin{tabular}{|l|l|l|l|}
\hline SI.No & Maternal Complications & No. of Cases & $\mathbf{\%}$ \\
\hline 1 & Pulmonary edema & 31 & 33.6 \\
\hline 2 & Abruptio Placentae & 19 & 20.6 \\
\hline 3 & CVA & 17 & 18.4 \\
\hline 4 & PPH & 8 & 8.6 \\
\hline 5 & Renal failure & 7 & 7.6 \\
\hline
\end{tabular}




\begin{tabular}{|l|l|l|l|}
\hline 6 & HELLP Syndrome & 6 & 6.5 \\
\hline 7 & CCF & 2 & 2.1 \\
\hline 8 & Aspiration Pneumonia & 2 & 2.1 \\
\hline Total & & 92 & $100 \%$ \\
\hline
\end{tabular}

Table 3 summarizes significant maternal complications in Eclampsia. The common complications were pulmonary oedema in 31 (33.6\%),Abruptio placenta in 19(20.6\%), CVA in 17 (18.4\%),PPH in 8 (8.8\%), renal failure in 7 (7.6\%),HELLP Syndrome in $6(6.5 \%)$, CCF in 2 $(2.1 \%)$ and Aspiration Pneumonia in $2(2.1 \%)$ cases. None of the surviving women had evidence of neurological deficit or seizures at the time of discharge.

Table 4 - Maternal Mortality $(\mathrm{n}=\mathbf{2 1})$

\begin{tabular}{|l|l|l|l|}
\hline Sl.No. & Maternal Death & No. cases & Percentage (\%) \\
\hline 1 & CVA & 7 & 33.3 \\
\hline 2 & Pulmonary Embolism & 5 & 23.0 \\
\hline 3 & Pulmonary Edema & 5 & 23.0 \\
\hline 4 & CCF & 2 & 9.5 \\
\hline 5 & Multi Organ Failure & 2 & 9.5 \\
\hline Total & & 21 & $100 \%$ \\
\hline
\end{tabular}

There were 21 maternal deaths out of 203 Eclampsia patients (1.8\%). Three died undelivered. The various causes for death were CVA in 7 (33.3\%), Pulmonary Embolism in 5 (23\%),pulmonary oedema in 5 (23\%),CCF in 2 (9.5\%) and multi organ failure in 2 (9.5\%).However they were all admitted in a moribund state.

The 166 pregnancies resulted in 163 births ( 3 patients died undelivered).There was 68 still births and 20 neonatal deaths for a total perinatal mortality of $44.3 \%$ which is largely due to prematurity. $56.2 \%$ patients had live and healthy babies. Most of the patients had low birth weight, $65.7 \%$ had birth weight

$<2.5 \mathrm{~kg}$ and $11 \%$ had birth weight $<1.5 \mathrm{~kg}$

The 166 pregnancies resulted in 163 births (3 patients died undelivered).There was 68 still births and 20 neonatal deaths for a total perinatal mortality of $44.3 \%$ which is largely due to prematurity. $56.2 \%$ patients had live and healthy babies. Most of the patients had low birth weight, $65.7 \%$ had birth weight $<2.5 \mathrm{~kg}$ and $11 \%$ had birth weight $<1.5 \mathrm{~kg}$

DISCUSSION: The high incidence of Eclampsia can be reduced by proper antenatal care and admitting and treating mild cases of hypertensive disorder of pregnancy cases and training the Medical Officers at the Peripheral Health Centers regarding immediate management of Eclampsia.

Pregnancies complicated by Eclampsia are associated with poor maternal and perinatal outcomes. The reported maternal mortality ranges from $0.4 \%$ to $14 \%$ depending on the 
experience and facilities of the reporting centre, as well as the condition of the women on admission to the centre. ${ }^{11}$

Magnesium sulphate was commonly used drug as anticonvulsant. In our study $68.9 \%$ had no convulsion after loading dose,30.2\% had subsequent seizures after receiving loading dose and needed additional anticonvulsant drug. These finding emphasize the need for close monitoring of all women with Eclampsia during and labour and postpartum. Many referring doctors have little or no experience regarding management of Eclampsia .It is recommended that the women should be stabilized regarding blood pressure and control of convulsions before transport and they should be sent in an ambulance with medical personnel in attendance. Tertiary care centre should have a backup with facilities to manage critical maternal complications and provide intensive care to the immature infant.

CONCLUSION: This study highlights that we are still facing the challenges of this life threatening complication. Depicting the severe disease spectrum, it reflects upon the unmet need of prenatal care in our community.

The community should be educated regarding importance of antenatal care specially during last trimester. Immediate referral to a tertiary care centre is necessary in all patients with morbid symptoms of pregnancy induced hypertension. Early delivery by caesarean section \& upgrading neonatal facilities can improve the maternal as well as perinatal outcome.

Vigilant Antenatal, Intranatal \&Postnatal management of all such patients will improve maternal and foetal outcome related to Eclampsia.

\section{REFERENCES:}

1. Chesley LC. History: Hypertensive disorders in pregnancy. New York r- CenturyCrofts , 1978; $17-34$

2. Kumar Majhi A,SarathyChakraborty P, MukhoPrdhyaya A; Present scenario in a referral medical college Calcutta. J.ObstetGynaecol India 2000;50:128-32

3. CondeAgudelo,Belizan JM 2000- Risk factors pre-eclampsia in a large cohort of American and Caribbean women,Br. J. ObstetGynaecol; 2000;107:75

4. SibaiBM Eclampsia. In:RulinaPC,ed.Handbook of Hypertension in pregnancy. Amsterdam; Elsevier Science,1988,Vol.10:320-40

5. ZuspanFP.Problemsencountered in the treatment of pregnancy induced hypertension. Am J Obstet Gynaecol.1978;131:591-7

6. Gilstrap LC $3^{\text {rd }}$.Cunningham FG, Whalley PJ.Management of pregnancy induced hypertension in the nulliparous patients remote from term.Semin. Perinatol1978;2:73-81

7. Pritchard JA , C unningham FG ,Pritchard SA . The Parkland Memorial Hospital Protocol for treatment of Eclampsia: Evaluation of 245 cases. Am J ObstetGynaecol 1984;148:951-63

8. Pickles CJ Broughton, Pipkin E;A randomized controlled trial of Labetalol in the treatment of mild to moderate pregnancy induced hypertension $\mathrm{Br} \mathrm{J}$. Obstet. Gynaeclol. 99, 964:1992

9. SibaiBM Eclampsia VI.Maternal- Perinatal outcome in 254 consecutive cases. Am J ObstetGynaecol 1990;163;1049-55

10. Desai P, Badheka H , Barbhaiya M.Changes in perinatal outcome due to Magnesium Sulphate in Eclampsia. J ObstetGynaecol India. 1995; 45:732-5 
11. Eskas TK, Leon C. Chesley,Hypertension in pregnant women.Eur. J. ObstetGynaecol report Biol.2000;90:181:6

Distribution of cases according to Gestational Age $(n=203)$

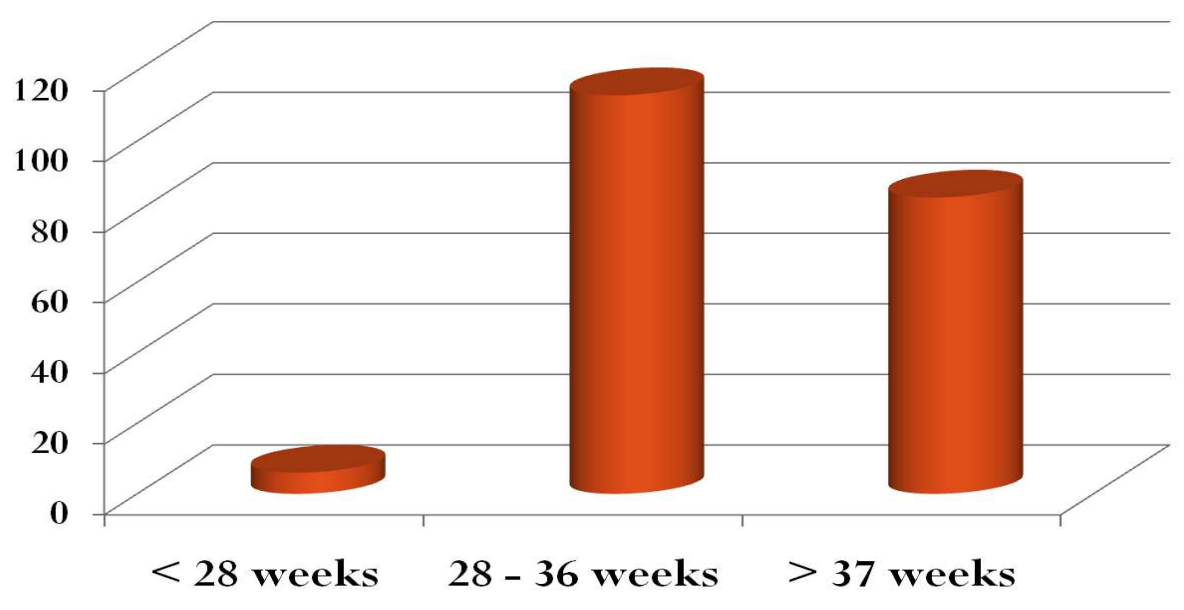

\section{Perinatal outcome-}

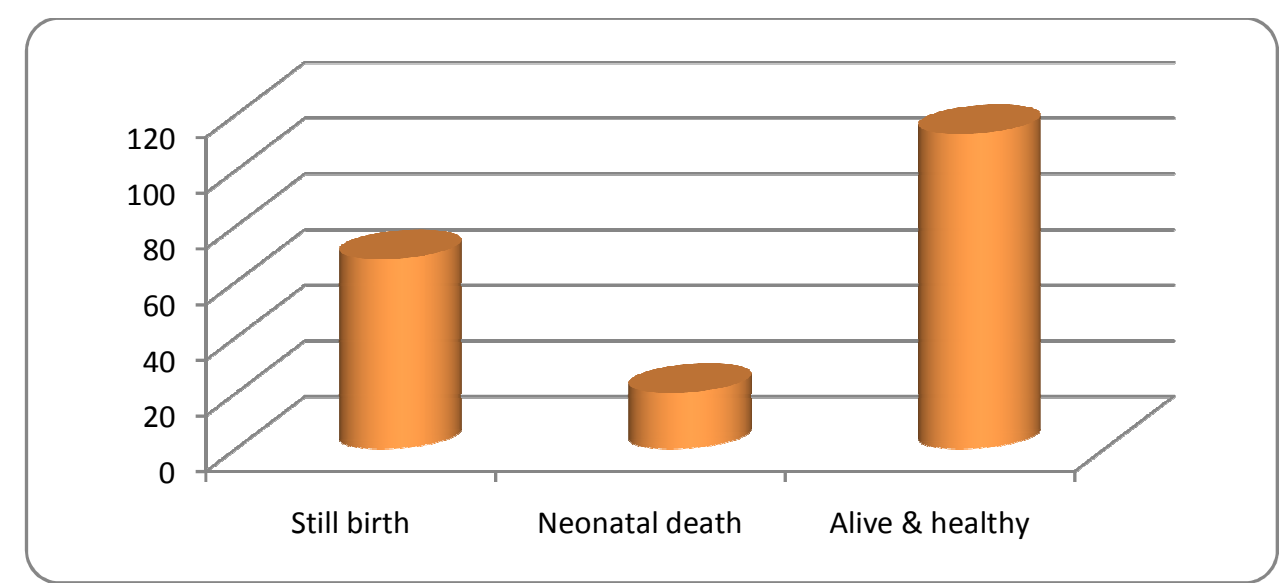

